\title{
Regenerative Braking in Electric Vehicles
}

\author{
C. S. Boopathi, Soutreyo Saha, Anvita Singh, Soumyajeet Sinha
}

\begin{abstract}
This paper deals with the implementation of regenerative braking in electric vehicles using PMDC motor. Regenerative braking is the transformation of the vehicle's energy when the brakes are applied into a stored energy in the battery, which can be used for some other applications within the vehicle. Short range distance covering characteristics of EVs has always beem a major setback for electric cars gaining popularity among users. The exclusive property of a hybrid electric vehicle to recover the energy lost in the form of heat when the driver applies brakes is a major advantage of a hybrid electric cars and has an edge over the other electric vehicles in the market. This problem is solved by increasing the range of these cars. The majority of the kinetic energy kept in a moving vehicle is wasted as heat and some part of it is absorbed by rolling resistance, mechanical friction and aerodynamics of the vehicle. The present day development to merge the drivetrain and brake systems to provide better traction and stability control can be made simpler with the use of electric drive operation. In this process we use simulation tools like simulink and solid works before going for real time circuit. Aim of this project is to create a sustainable future $\mathrm{EV}$ which will be a solution to the fuel crisis in near future.
\end{abstract}

Keywords: Regenerative braking, Electric vehicle, Simulink, PMDC motor

\section{INTRODUCTION}

Renewable energy systems are widely getting accepted and becoming well-organized. These are alternate ways that could possibly lead us away from the petroleum dependent energy resources. In this project the concept of regenerative braking $[1,2]$ is implemented with a PIC controller and buck converter. In the prototype model a flywheel has been designed and the modeling of the same has been done[3]. Two PMDC (Permanent Magnet Direct Current) motors have been used. One motor has been used for the first quadrant operation (Motoring) and the second motor is used for fourth quadrant action (Regenerative Braking). The voltage from the flywheel is given to the buck converter. The switching of the buck converter is done using a PIC controller and a driver circuit consisting of an opto-coupler. The supply to both PIC controller and driver circuit is given using transformers. The output from the proposed circuit is in the range of $0-4 \mathrm{~V}$ and the current is in the range of $0-14 \mathrm{~mA}$..

\section{PMDC Motor}

A PMDC motor is a DC motor. PMDC stands for permanent magnet direct current motor. As the name suggests the permanent magnets create a magnetic field and

Revised Version Manuscript Received on 10, September 2019.

Dr.C.S.Boopathi, SRM Institute of Science and Technology, Kattankulathur, Chennai, Tamil Nadu, India.

SoutreyoSaha, SRM Institute of Science and Technology, Kattankulathur, Chennai, Tamil Nadu, India.

Anvita Singh, SRM Institute of Science and Technology, Kattankulathur, Chennai, Tamil Nadu, India.

SoumyajeetSinha, SRM Institute of Science and Technology, Kattankulathur, Chennai, Tamil Nadu, India. the stator windings are not present. The outer casing on which the permanent magnets are fixed is made out of steel and is made in a cylindrical shape. There are slots on the armature which carries armature winding. Layers of laminated silicon steel are used to make the rotor in order to reduce eddy current losses. These motors are used where power rating required is small e.g. remote control cars, hand held fans etc.

\section{Advantages of PMDC motor}

- Less manufacturing cost.

- Field excitation is not needed.

- Construction cost is less.

- More efficiency.

- Small in size.

\section{Buck-Converter}

A buck converter is a type of dc-dc step down converter which falls in the category of power converters. It belongs to the group of SMPS (switched mode power supply) which contains two semiconductors. These type of switching converters provides higher power efficiency as compared to other converters of the same type. Linear regulators have a comparatively easier circuit that lowers voltages by releasing power as heat but they do not increase the output current. During the ON state the diode is reverse biased, the current will be stored in the capacitor. Consequently in the OFF state the current stored in the capacitor flows through the diode and makes it forward biased.
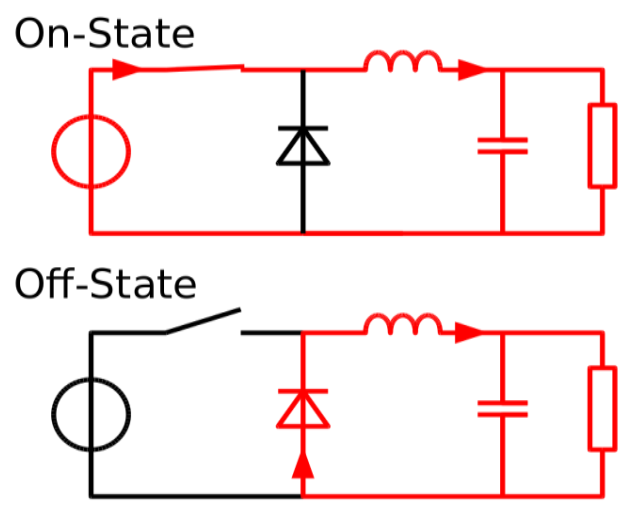

Figure 1: Working of buck converter

\section{Inductor Selection}

Data sheets often provide us with recommended inductor values. In the buck converter circuit the inductor is chosen to be of a higher value[6]. As we know that the value of inductance and the maximum outputcurrent are proportional to each other. As a result of which if one value increases the latter increases correspondingly and due to the reduction in

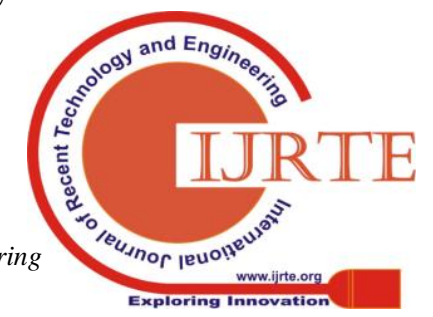




\section{REGENERATIVE BRAKING IN ELECTRIC VEHICLES}

the ripple current the inductor should maintain more current rating compared to the peak current. This is because the current is inversely proportional with the inductance.

\section{Input Capacitor Selection}

The least value required for the selection of input capacitor[4] can be referred from the data sheet. This attainable value is important in order to regulate the input voltage for the required peak current of a switching power supply. The easiest way is to use ESR ceramic capacitors.[5] The dielectrci should be X5R or else, the capacitor will lose consierable amount of its capacitance because of the temperature. The value can be improved if the dc voltage is distorted.

\section{Output Capacitor Selection}

The easiest way is to use equivalent series resistance capacitors to reduce the distortion in the output voltage. Ceramic capacitors are convinient to use if the dielectric material is X5R. If the converter has external compensation, any value of capacitor more than the prescribed minimum value from the data sheet can be used, but the compensation needs to be adjusted for the already utilised output capacitance. From the internally compensated converters, suggested inductor and capacitor values should be taken, or the recommendations in the data sheet for fine tuning the output capacitors to the application in the data sheet needs to be followed in the proportion of $\mathrm{L} \times \mathrm{C}$.

\section{Driver circuit}

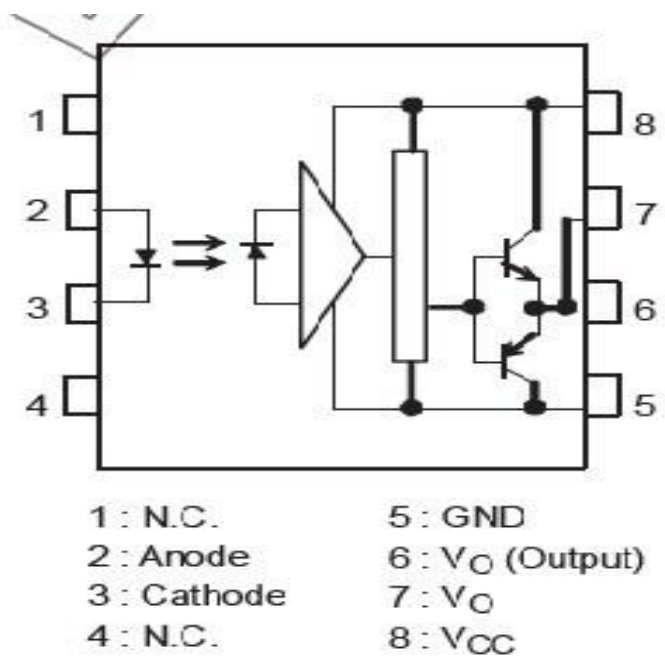

Mosfet driver TLP250 used in the proposed circuit similar to other MOSFET drivers has two stages namely an input stage and an output stage. It has a source configuration.TLP250 is compatible with both MOSFET and IGBT and in this case is used with MOSFET. The main advantage of TLP250 over other MOSFET drivers is that TLP250 MOSFET driver is optically isolated. It implies that both the input and output of TLP250 are confined from one another. It works like a optocoupler. Input stage have a light emitting diode and output stage have photo diode. As soon has the LED light falls on the photo detector diode, output becomes high. Thus to regulate smaller devices that operates on DC, a transistor-based driver circuit can be used to improve the current to the extent required for the device to operate. When output levels are in the desired range, the transistor behaves like a high-current switch regulated using the lower current digital logic signal.

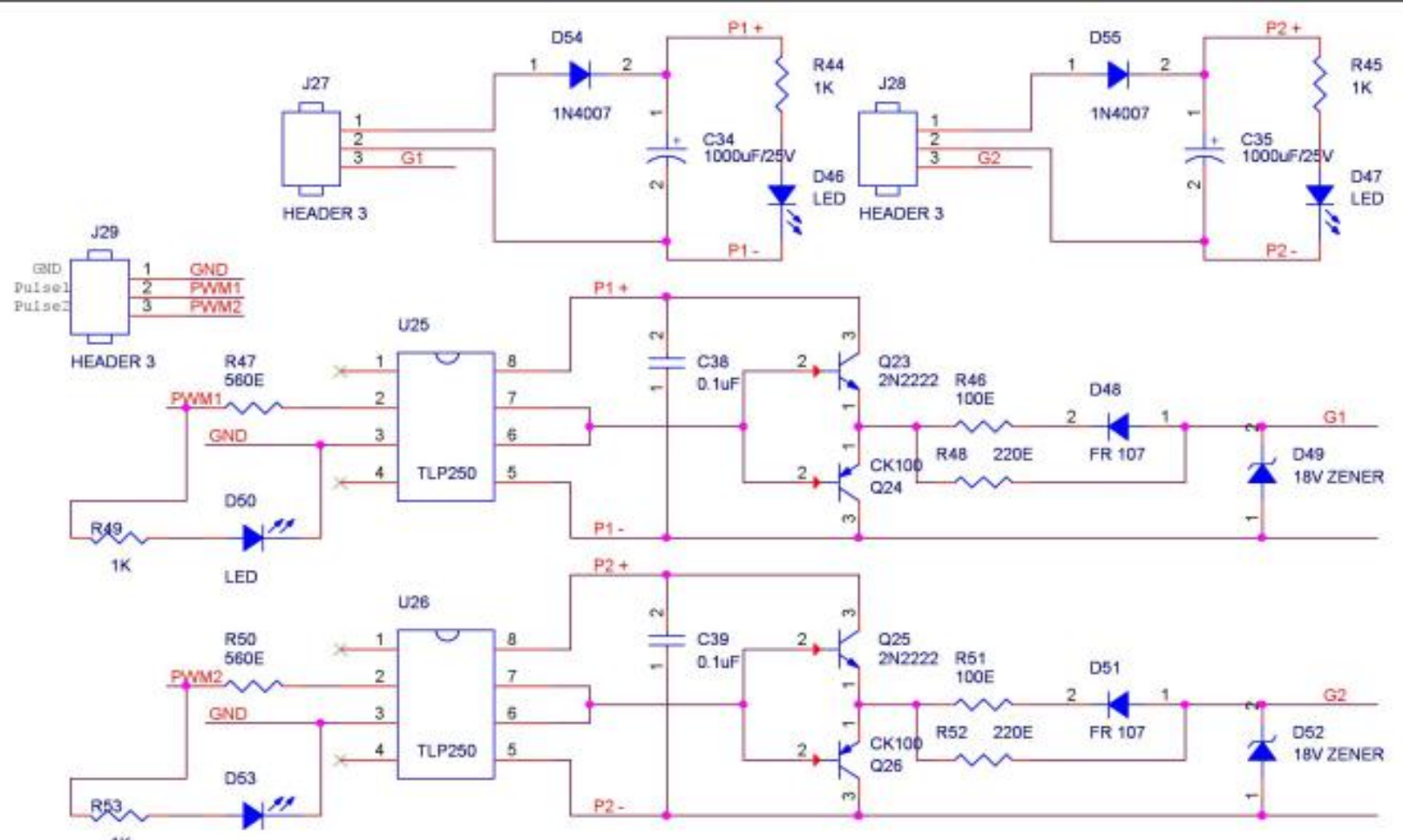

Figure 2: Circuit diagram of driver circuit 
Here the driver circuit is used to amplify the voltage received from the PIC controller which is further given to the buck converter as a switching signal.

\section{PIC Microcontroller}

PIC (Peripheral Interface Controller) belongs to the family of microcontrollers manufactured by Microchip technology. Earlier PIC microcontrollers used to have ROM (Read Only Memory) or field programmable EEPROM for program storage. The recent models have flash memory for program storage also the program memory and data memory are separated from each other. There are different instruction sets for different models. PIC devices are very popular amongst industries and research scholars due to their low cost, wide availability, serial programming.

For our proposed model we have used PIC 16F877A PORT A, PORT B, PORT C an PORT D.

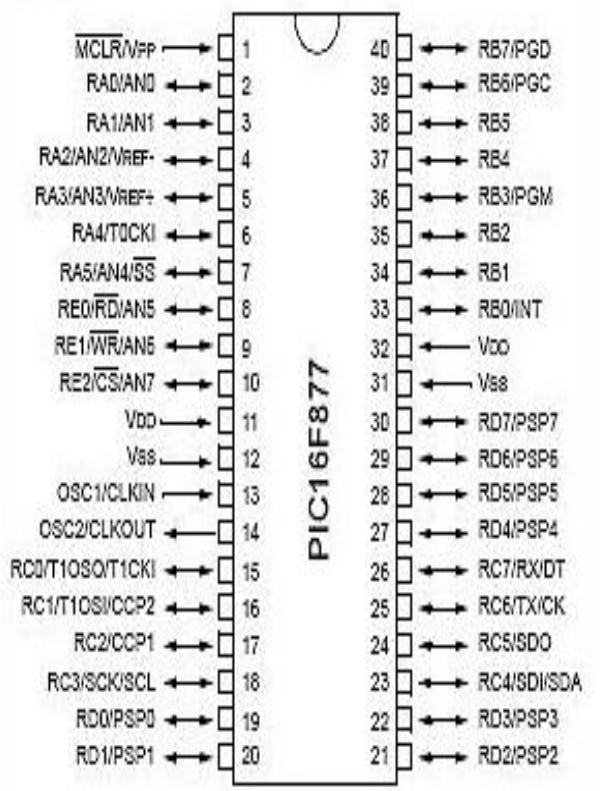

Figure 3: Microchip 16F877A

It has 2 Pins TX and RX for serial communication. $\mathrm{RX}$ is for receiving data and TX is for transmitting data. It supports SPI protocol as well. 8 pins in Port A are analog and Port B also has 8 pins but these 8 pins are digital pins. Port $C$ is also a digital port same as that of Port B. Pins in Port $\mathrm{C}$ pins are used for serial communication. Port D has 8 pins which are all digital pins.

\section{Arduino Uno}

Arduino Uno uses an ATmega 328P microcontroller which consists of a Flash Program Memory(32 kbytes), an EEPROM Data Memory(1 kbytes), SRAM Data Memory(2 kbytes). The Arduino Uno board has 14 digital I/O pins, out of which 6(D3,D5, D6,D9,D10, and D11) can be used as PWM outputs, 6 are analog inputs, which can also be used as digital I/O pins, adding to the existing 14 digital I/O pins. It has only one serial communication line (D0,D1).

\section{Flywheel Modeling}

A flywheel is a mechanical device and is mainly designed to store rotational energy. Flywheels due to it's moment of inertia does not get easily affected by the changes in it's rotational speed. They are mainly used to provide regulated power output in systems where the energy source is not continuous. In this project the flywheel (Diameter $=180 \mathrm{~mm}$ and Thickness $=11 \mathrm{~mm}$ and Inner Dia $=10 \mathrm{~mm}$ ) is mounted on the primary motor shaft. The flywheel rotates along the motor shaft as long as there is motoring action. when the brakes are pressed, automatically the supply to the motor is cut. But the flywheel keeps rotating as long as there is some moment off inertia stored in it and that is used to rotate another secondary (regenerative) motor. The output of that motor is fed to the electronic circuit.

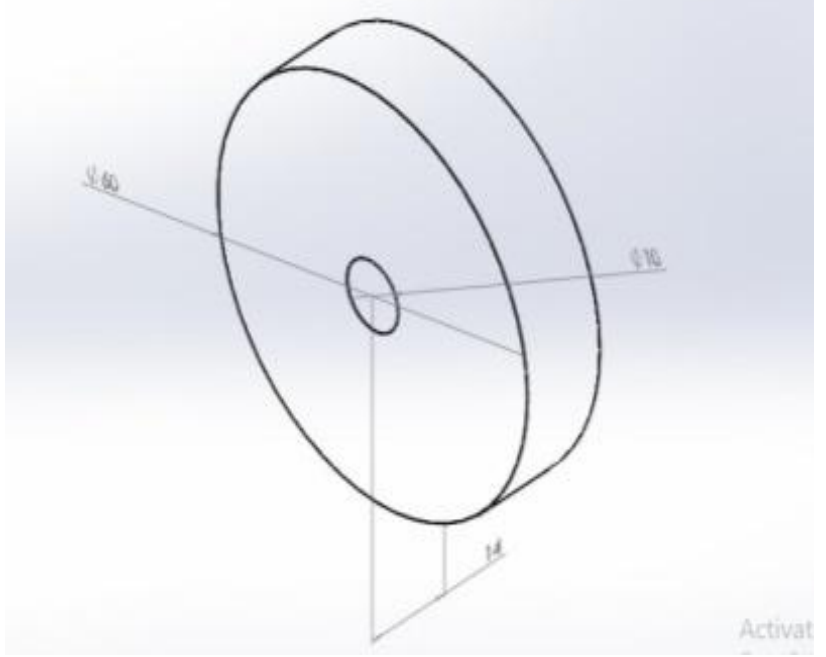

Figure 4: Flywheel $($ Diameter $=60 \mathrm{~mm}$ Thickness $=$ $1.4 \mathrm{~mm}$ and Inner Dia $=10 \mathrm{~mm}$ )

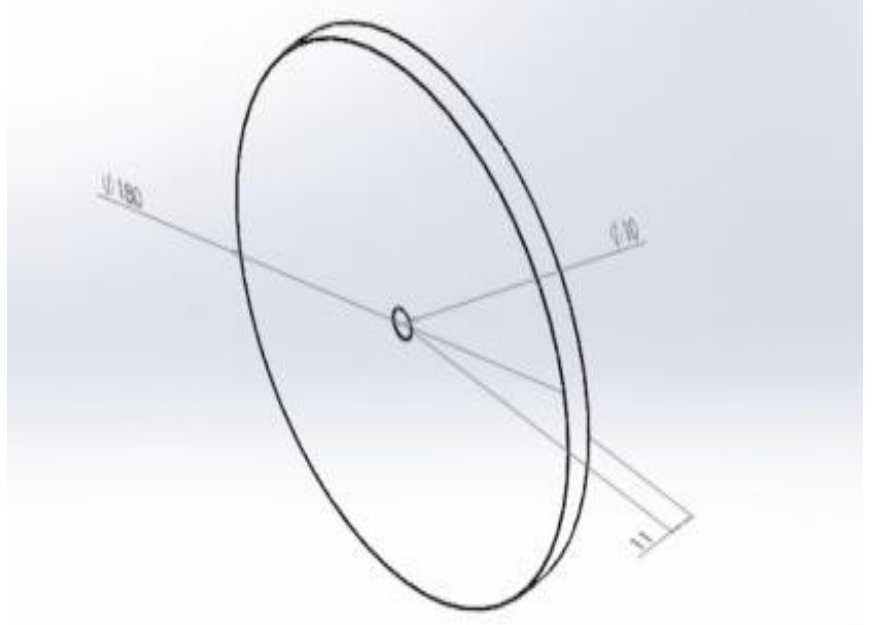

Figure5: Flywheel (Diameter $=180 \mathrm{~mm}$ and Thickness $=1.1 \mathrm{~mm}$ and Inner Dia $=10 \mathrm{~mm}$ ) 


\section{REGENERATIVE BRAKING IN ELECTRIC VEHICLES}

\section{Relay}

A relay is an electro-mechanical switch which is operated electrically. The current flowing through the relay coil forms a magnetic field which attracts a magnetic plate and causes it to change it's contacts. The coil current can be off or on, so relays have two switch positions.A relay can be used to switch on a second circuit which can be completely different from the first one. In this project, a relay has been used to switch the supply to the motor on or off depending on the position of the brake pedal.
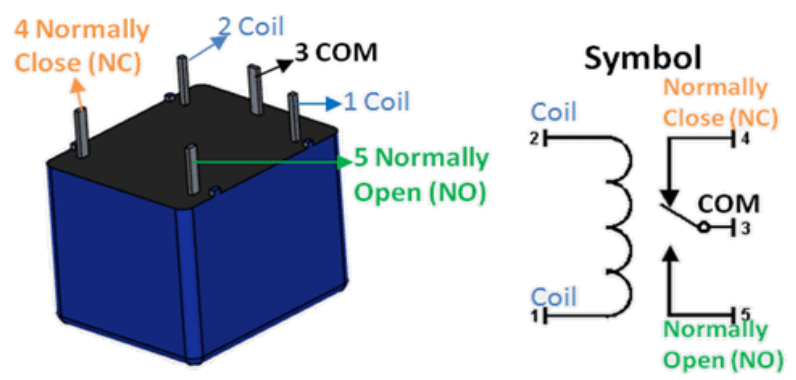

Figure 6: Relay pinout

\section{PROPOSED MODEL BLOCK DIAGRAM}

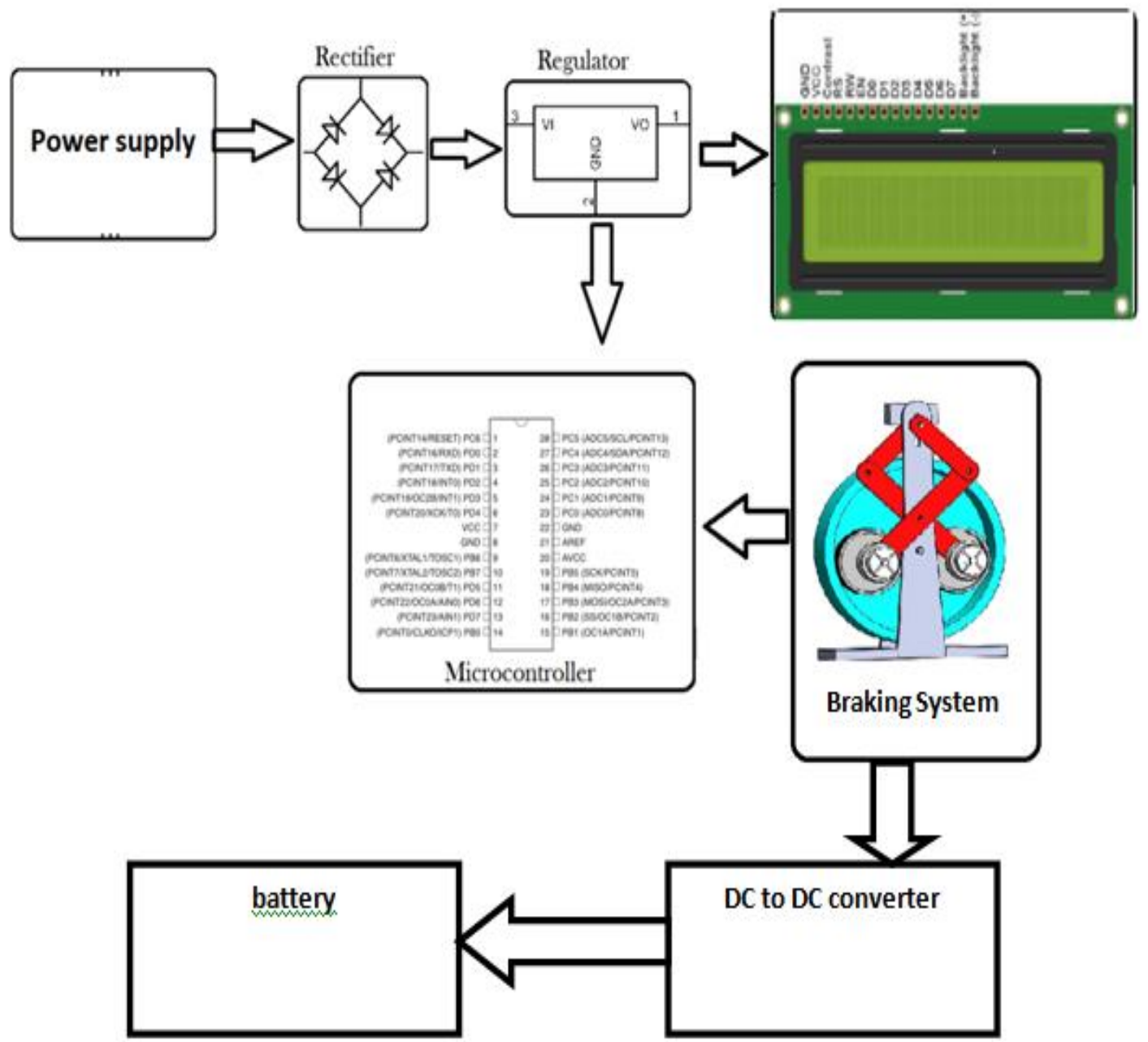

Figure 7: Block diagram of Proposed model

\section{CIRCUIT EXPLANATION}

The proposed model uses a 12V , $100 \mathrm{rpm}$ PMDC motor with a acrylic flywheel.A $6 \mathrm{~V}$ relay is used to control the supply to the motor terminals depending on the position of the brake pedal. As per the latching mechanism connected with the brake pedal, at the instant when the driver presses the brake pedal the hydraulic fluid from the brake oil chamber forces the piston attached with the regenerative motor to mechanically connect to the primary flywheel and as a result of this the coil of the relay gets energized and correspondingly the supply to the primary motor gets disconnected, But the flywheel does not stop rotating because of inertia. The output of the secondary motor is fed to the buck circuit. We get voltage output from the secondary motor terminals as long as the primary flywheel rotates. The MOSFET of the buck circuit is switched by the driver circuit. The input of the driver circuit is given from the PIC microcontroller which is used for controlling the output from the buck converter. The supply to both the driver circuit and PIC micro controller is given by two transformers of $220 \mathrm{~V}$. A LCD display coded with arduino is used for displaying the output voltage and current.

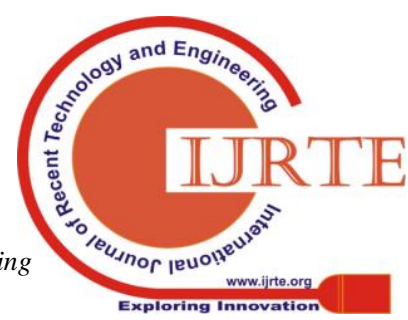




\section{SIMULATION OF THE PROPOSED MODEL}

Wind turbine is giving a torque input to the DC motor. So the motor will act as a generator.The switch is acting as a brake paddle. If it is connected to the turbine output it produce regenerative action and if it is connected to the other side it will give motoring action. When the switch is connected to the constant block the armature of the motor is connected to the battery terminals and the motor will take power from the battery. The motor now runs on the
battery(Motoring action). When the motor is given the turbine output then the controller action will come in. The controller will provide buck or boost operation depending on the motor voltage. If the motor voltage is more than the reference voltage then there will be boost operation and if it is less then there would be buck operation i.e. regenerative action. The controller is acting as a subsystem which consists of a comparator for comparing the voltage with the reference value and also a PI controller which will tune the error voltage according to the reference voltage.

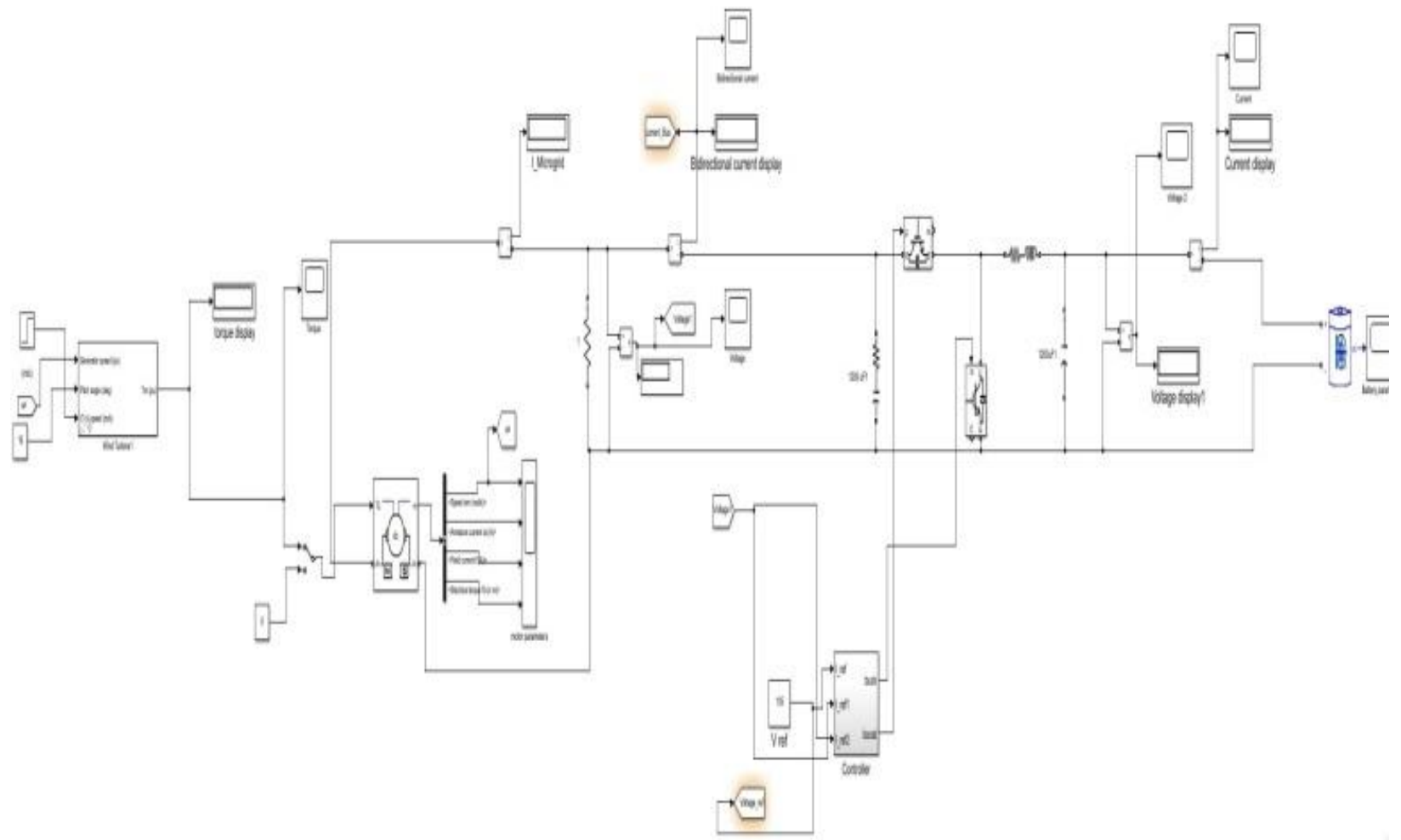

\section{SIMULATION RESULTS}

\section{Motoring Bidirectional Current}

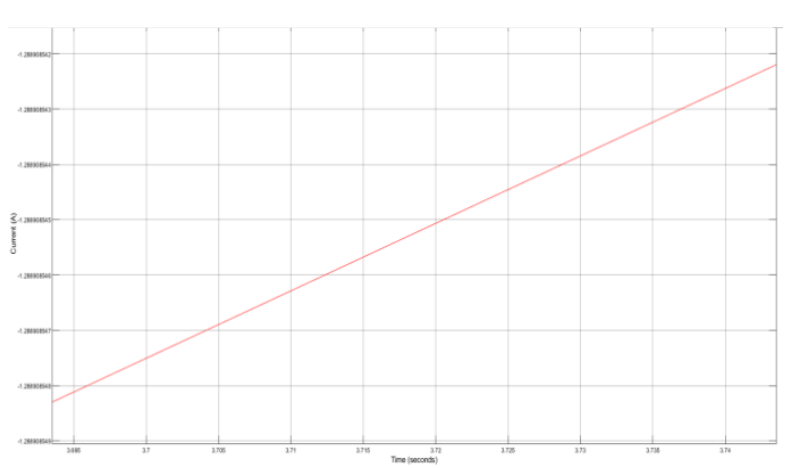

\section{Battery Characteristics}


REGENERATIVE BRAKING IN ELECTRIC VEHICLES

\section{Motoring parameters}
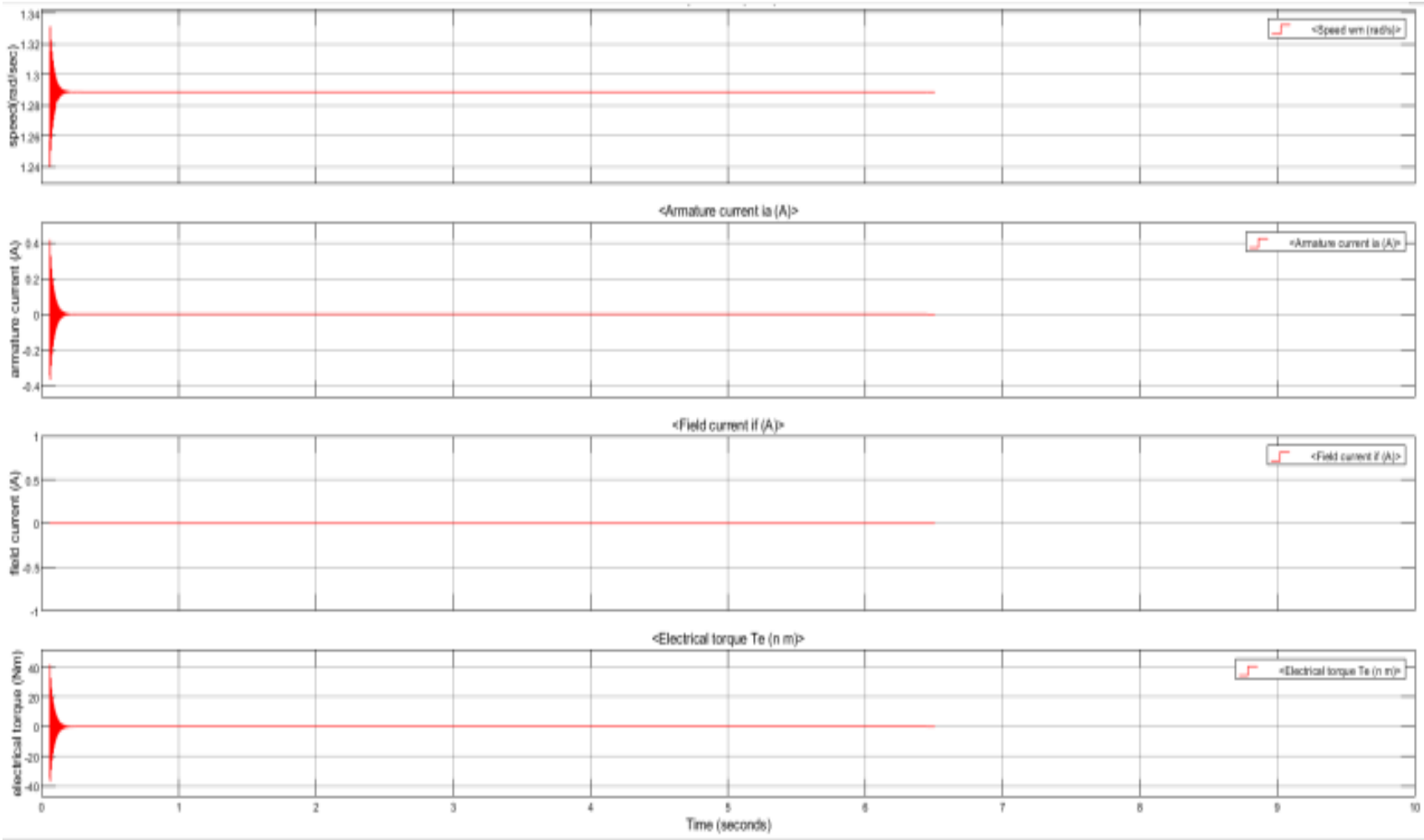

4. Regenerative Current 1
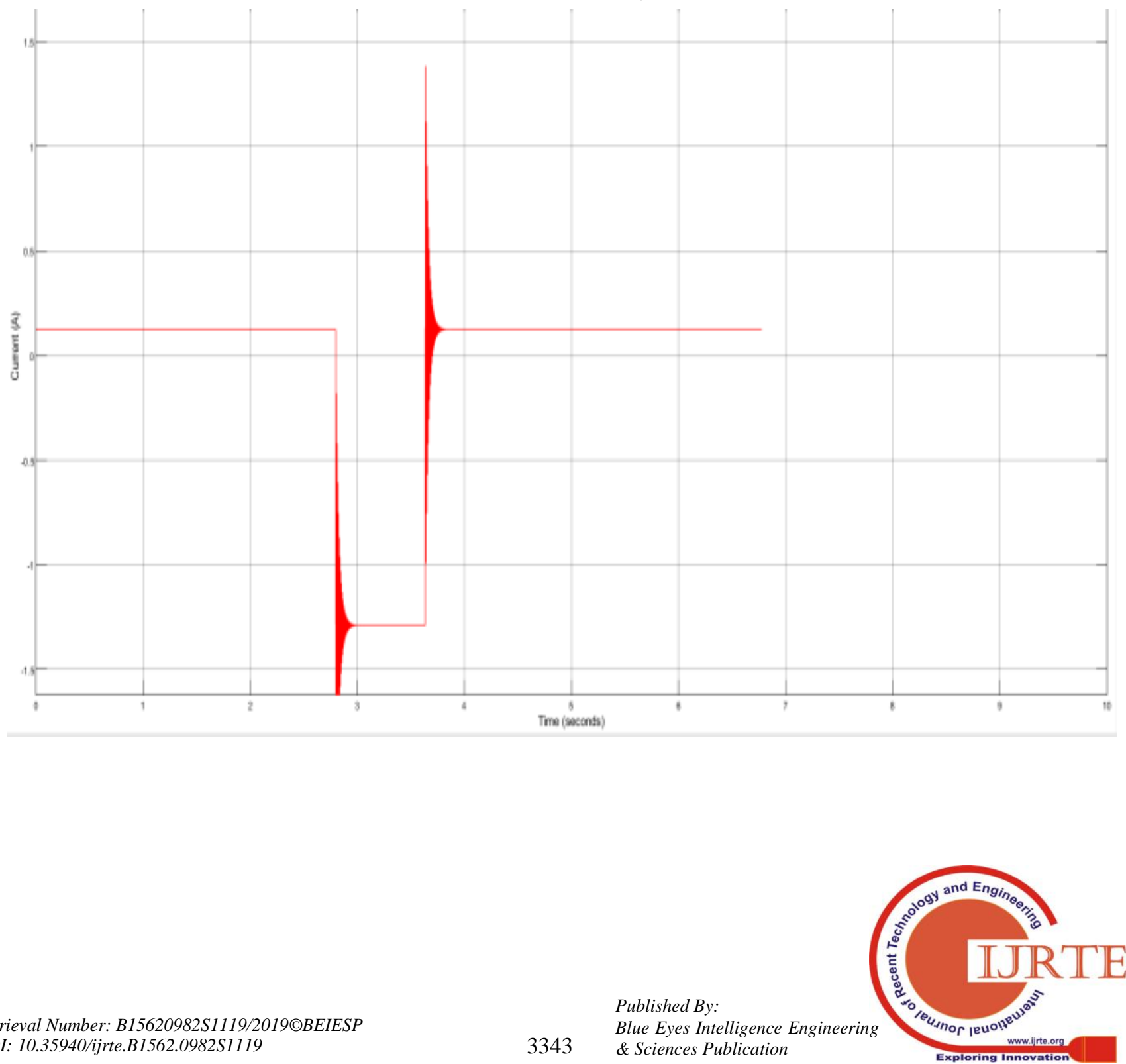
5. Regenerative Current 2

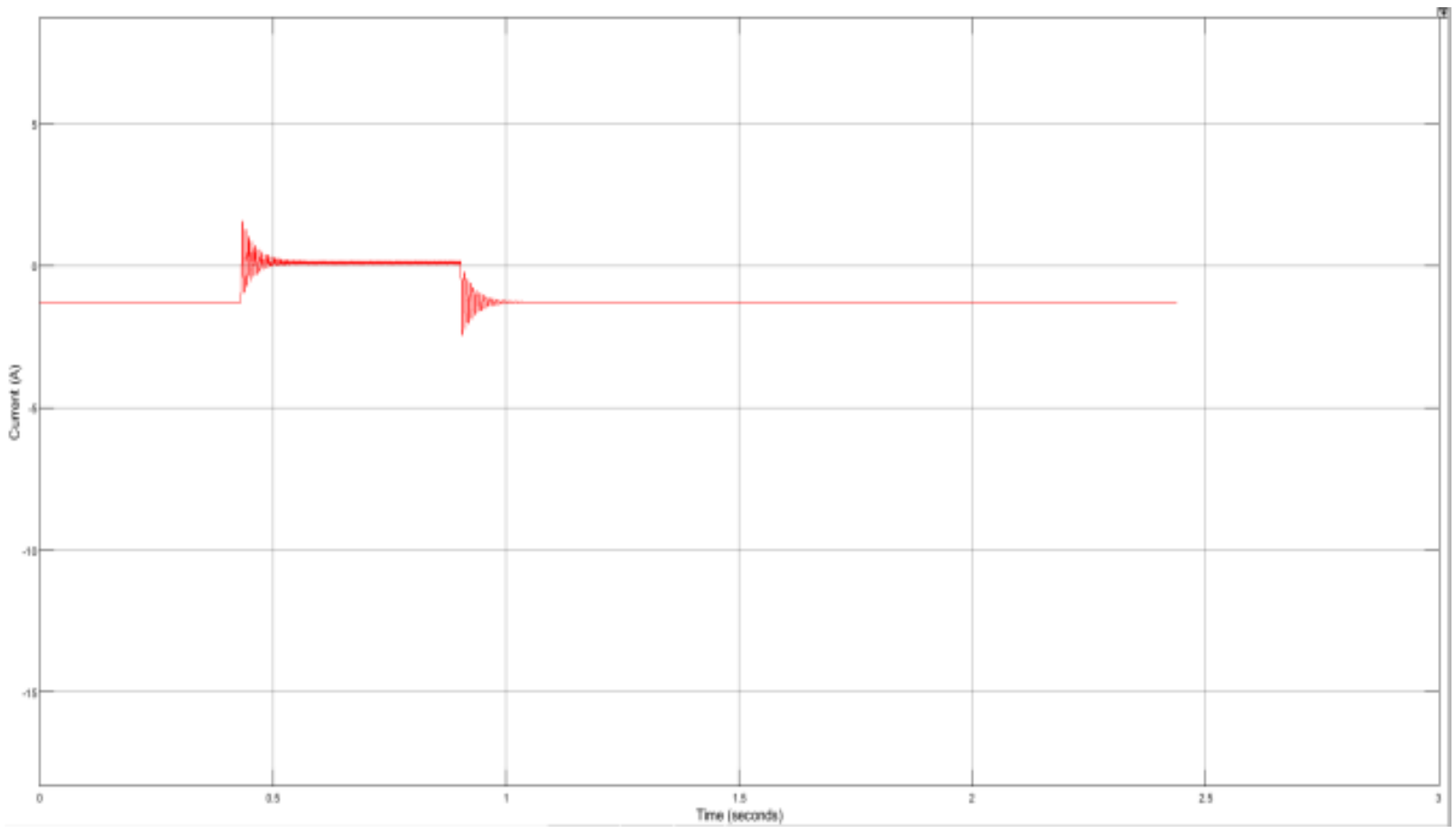

6. Regenerative Motor Parameters
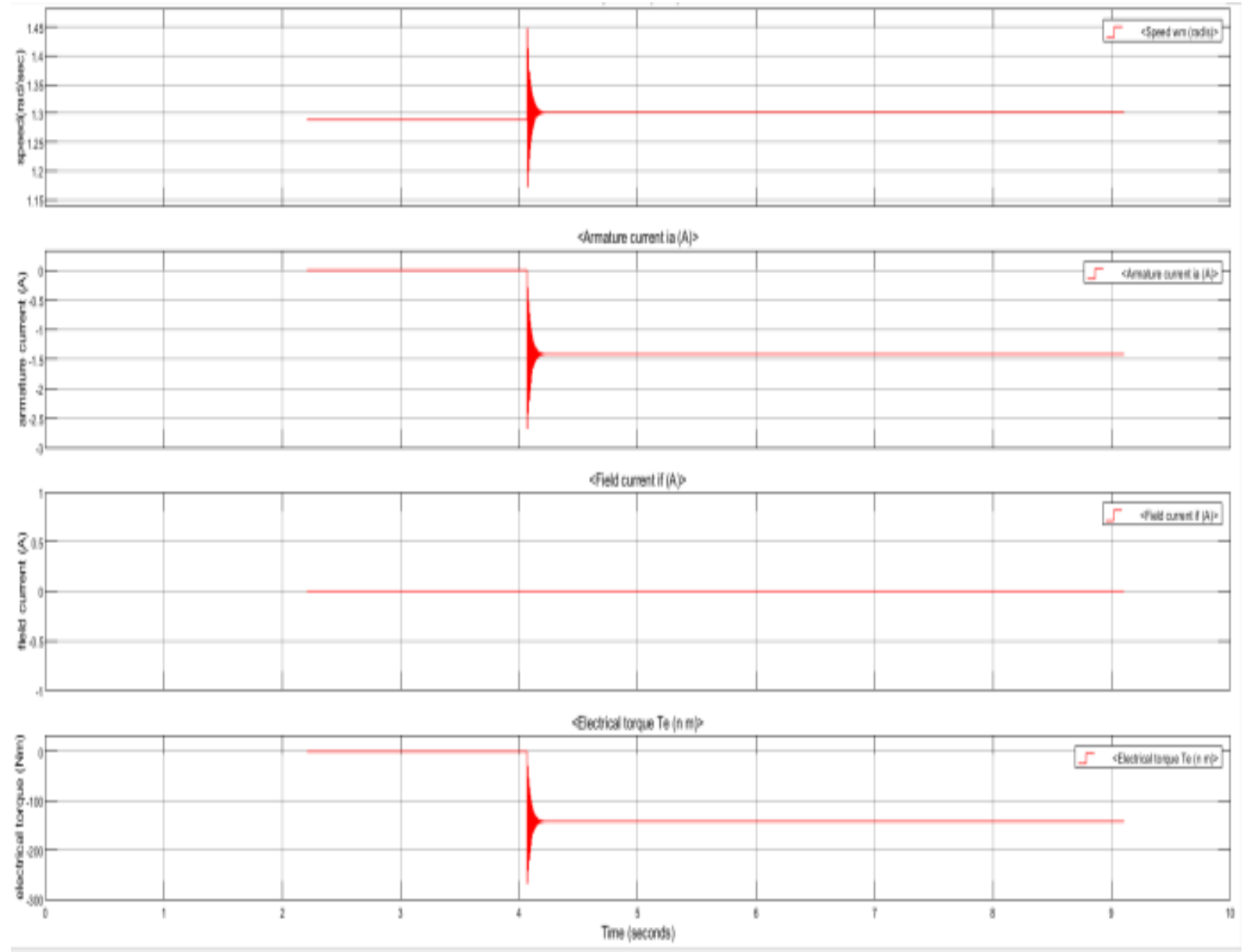


\section{Regenerative Voltage}

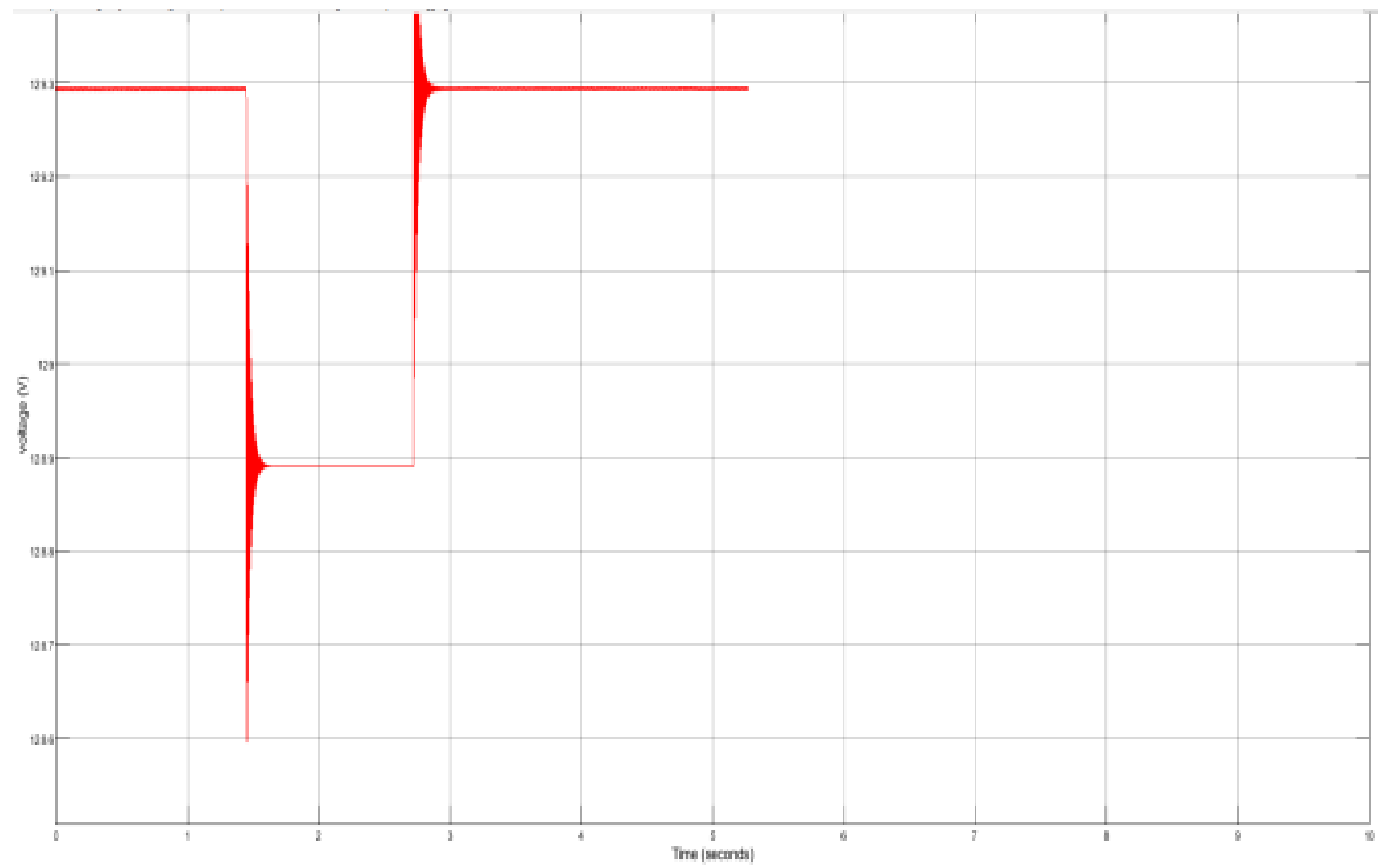

VI. HARDWARE IMPLEMENTATION

\begin{tabular}{|l|l|}
\hline Component Name & Rating \\
\hline Inductor & $0.5 \mathrm{mH}$ \\
\hline Capacitor & $1000 \mu \mathrm{F}$ \\
\hline Transformer & $230 \mathrm{~V}$ \\
\hline Motor & $12 \mathrm{~V}, 100 \mathrm{rpm}$ \\
\hline PIC Microcontroller & $16 \mathrm{~F} 877 \mathrm{~A}$ \\
\hline Optocoupler & $\mathrm{TLP} 250$ \\
\hline Relay & $9 \mathrm{~V}$ \\
\hline
\end{tabular}

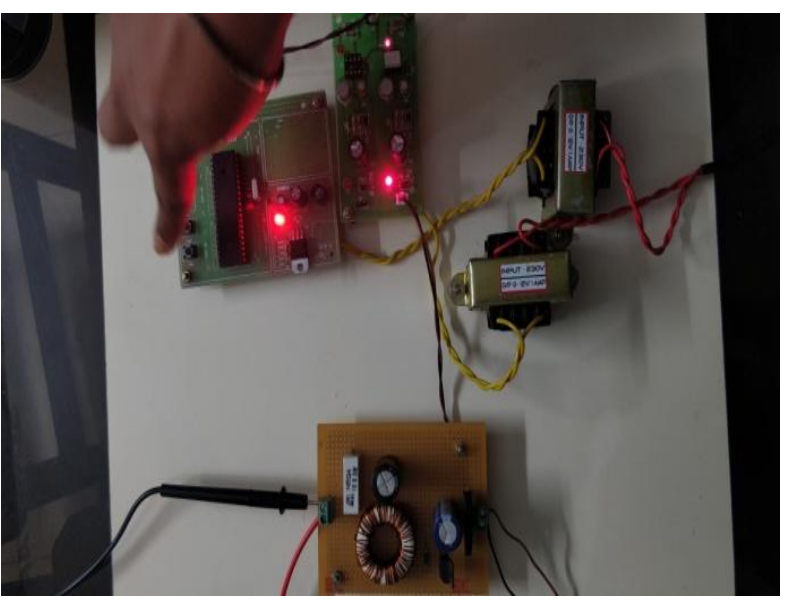

Figure 9: The electronic setup

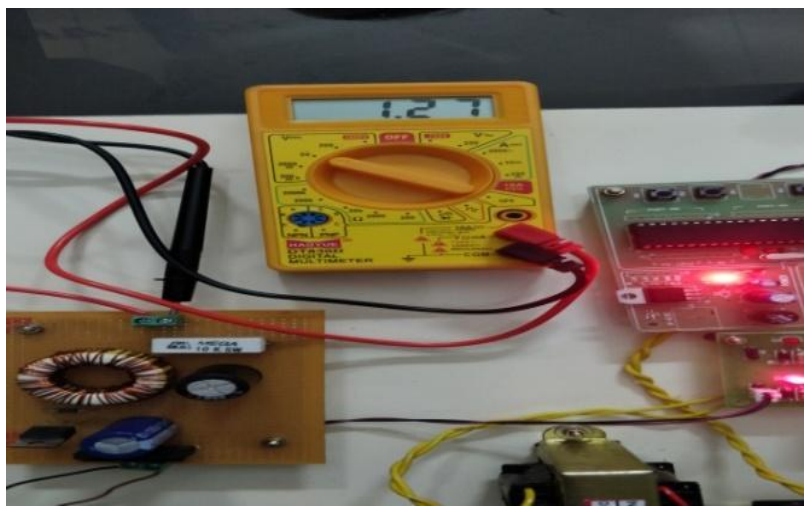

Figure 10: Regenerative voltage output

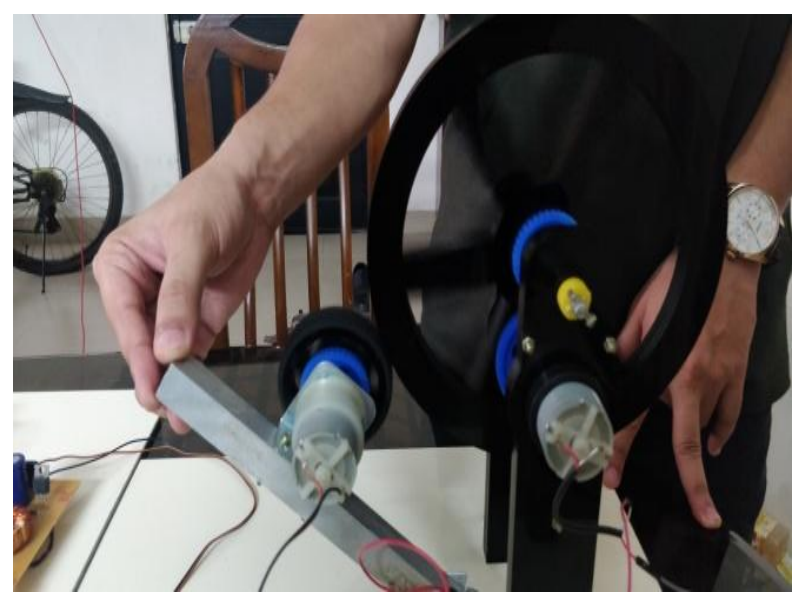

Figure 8: The mechanical setup

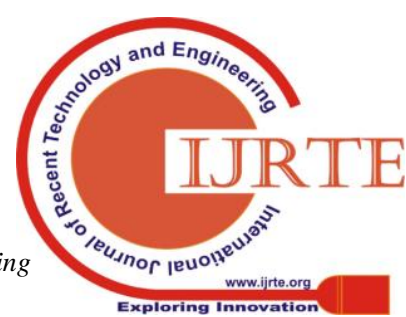




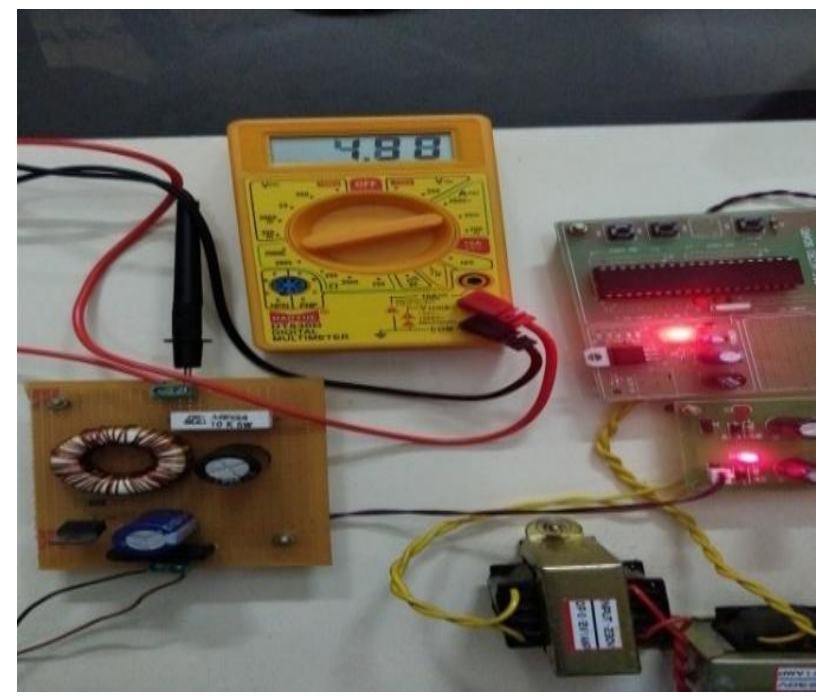

Figure 11: Regenerative current output

\section{CONCLUSION}

The rate of increase in pollution recently has been alarming and vehicles using petrol and diesel have a major contribution in it thus to control both the pollution and oil usage hybrid electric vehicles are the best alternative. Regenerative braking system using a buck converter and a PMDC motor has been simulated via simulink and the same is controlled by PIC microcontroller has been successfully implemented in the hardware.

\section{REFERENCES}

1 Samy M. Ghania,"Study of regenerative braking of electrical vehicles".

2 MamadouBaïloCamara, Hamid Gualous, Frederic Gustin, and Alain Berthon," Design and New Control of DC/DC Converters to Share Energy Between Supercapacitors and Batteries in Hybrid Vehicles", IEEE TRANSACTIONS ON VEHICULAR TECHNOLOGY, VOL. 57, NO. 5, SEPTEMBER 2008.

3 AgnaPrince,Peter K. Abraham,Aryanandini B,' Design and Implementation of Ultra Capacitor Based Rege,nerative Braking System for a DC Motor", Proceeding of 2018 International Conference on Emerging Trends and Innovations In Engineering and Technological Research (ICETIETR).

4 Khaled Itani Alexandre De Bernardini,ZoubirKhatir ,Ahmad Jammal „Mohamad Oueidat," Extreme conditions regenerative braking modeling, control and simulation of a hybrid energy storage system for an electric vehicle ", DOI 10.1109/TTE.2016.2608763, IEEE Transactions on Transportation Electrification.

5 K. Selvakumar, C. S. Boopathi, C.Sakthivel and T.Venkatesan., (2016) "Design and Implementation of a Converter Model for Hybrid Electric Vehicle Energy Storage System", International Journal of Control Theory and Applications, 9(14), pp. 6787-6795

6 Sreejith. S, V. Indragandhi, K. Chandrasekaran, A. Venkadesan and C.S. Boopathi., (2016) "Analysis of PV Based Energy Generation System Using Cascaded Multi-level Z-Source Inverter" International Journal of Control Theory and Applications, 9(37), pp. 837-843 